\title{
Jóvenes titulados superiores en la encrucijada de la crisis ${ }^{1}$
}

\author{
Young Graduates at the Crossroads of Crisis
}

\author{
ALESSANDRO GENTILE \\ FaCUlTAD DE CIENCIAS SOCIALES Y DEL TRABAjO \\ UNIVERSIDAD DE ZARAGOZA
}

Artículo recibido: 4 junio 2014

Solicitud de revisión: 11 noviembre 2014

Artículo aceptado: 13 enero 2015

\begin{abstract}
Resumen
La crisis económica hace más difícil la transición a la vida adulta. Ni siquiera los jóvenes universitarios están a salvo de la precariedad laboral. Hemos entrevistados a veinte españoles entre 20 y 30 años, con títulos académicos y con trabajos precarios para saber cómo la coyuntura actual influye en sus posibilidades de independencia. A través de sus posicionamientos interpretativos, describimos la crisis como trampa, obstáculo o desafío. La alteración de su emancipación es un reflejo de los problemas de relevo generacional y de promoción social que las familias de clase media están experimentando en nuestro país en los últimos años.
\end{abstract}

Palabras clave: transición a la vida adulta, estudios universitarios, precariedad laboral, privación relativa, análisis del discurso.

\begin{abstract}
The economic crisis has increased the difficulty of the transition to adulthood. Neither young people with academic degrees can avoid employment instability. We interviewed twenty Spanish young-adults between 20 and 30 years old, with bachelor degrees and precarious jobs in order to know how the current economic downturn is influencing their possibility of independence. According to their interpretative perspectives, we describe the crisis as a trap, as an obstacle or as a challenge. The changes of their emancipation patterns are the spitting images of those problems related to generational replacement and social promotion that Spanish middle-class families have been experimenting during the last years.
\end{abstract}

Keywords: transition to adulthood, academic degree, job precariousness, relative privation, discourse analysis.

1 El artículo ha sido redactado en el marco del proyecto «La transición de los jóvenes a la vida adulta. Crisis económica y emancipación tardía» de la Fundación La Caixa de Estudios Sociales (2012), coordinado por Almudena Moreno de la Universidad de Valladolid, y del proyecto SolfCARE, «Solidaridad familiar, cambio actitudinal y reforma del Estado de Bienestar: el familismo en transición", Plan Nacional I+D 2011-2014, coordinado por Pau Marí-Klose de la Universidad de Zaragoza. Muchas gracias a Irene Crespo, Pablo González, Carolina Herrero, Javier López, Alba Méndez, Maite Molina y Sixto Villalba por haber colaborado en la realización de este estudio. 


\section{INTRODUCCIÓN}

Los jóvenes españoles viven el presente con poca seguridad y con mucha inestabilidad para el futuro. Las nuevas generaciones son conscientes de que la formación se extiende a lo largo de toda la vida, pero no necesariamente les permitirá integrarse en la sociedad como quisieran. Además, participan en el mercado de trabajo sabiendo que su empleo no será para siempre y que las condiciones de trabajo pueden a menudo no adecuarse a sus expectativas salariales y profesionales. Las tensiones en estos ámbitos se han exacerbado con la crisis económica que empezó en 2008 pero aún no han sido exploradas en profundidad.

En este artículo destacamos cómo estas tensiones llegan a ser objeto de reflexión y preocupación entre los jóvenes para conocer el impacto de esta crisis en sus transiciones. Hemos realizado veinte entrevistas semi-estructuradas a jóvenes españoles entre 20 y 30 años, ${ }^{2}$ de clase media, con nivel de estudios superior (título universitario de grado o de licenciatura), que se encuentran en paro o con trabajos temporales y con salarios netos inferiores a 1.000 euros mensuales, residentes en la ciudad de Madrid y que en el momento de la entrevista viven en casa con al menos uno de sus padres.

Este colectivo de veinteañeros presenta algunos de los rasgos más destacados de la precariedad laboral que sufre su generación, como la inestabilidad contractual, la sobre-cualificación, los salarios bajos y la prolongada dependencia de su familia de origen. Aquí indagamos cómo ellos interpretan estas problemáticas en el despliegue de sus transiciones a la vida adulta. Más específicamente, los relatos que hemos recopilado se refieren a sus condiciones de trabajo, expectativas profesionales y estrategias de emancipación, y nos facilitan sus "posicionamientos discursivos e interpretativos» (Conde, 2009) para entender los efectos de la crisis actual en sus pautas de independencia y autonomía.

\section{EL PROCESO DE EMANCIPACIÓN EN EL MARCO DE UN NUEVO FAMILISMO}

En sus recorridos biográficos los jóvenes consolidan su emancipación asumiendo responsabilidades productivas (un empleo estable) y residenciales (un hogar autónomo), con el ulterior y eventual complemento de

2 En el apéndice se encuentran las fichas de nuestros entrevistados y los criterios utilizados para seleccionarlos. 
responsabilidades conyugales (mantener una relación de pareja) y parentales (maternidad y paternidad). Cada joven construye su independencia a lo largo de sus transiciones del sistema formativo reglado al mercado de trabajo y de la familia de origen a una vivienda separada.

La familia como grupo primario de socialización y fuente de solidaridad y apoyo durante este proceso, representa para los jóvenes el punto de partida y el referente principal para desarrollar sus transiciones (López Blasco, 2006). Este pacto generacional es central y típico del contexto de emancipación de los jóvenes en el sur de Europa (Flaquer, 2004) y sigue la línea de descendencia de todos los integrantes de un mismo hogar: los adultos se dedican a la asistencia de las personas mayores y de los hijos, conscientes de que sus padres hicieron lo mismo en el pasado, y seguros de que sus hijos les asistirán cuando ellos se retiren de la vida activa.

Las relaciones paterno-filiales son menos autoritarias y jerárquicas que en el pasado: la convivencia bajo el mismo techo se mantiene gracias al respeto de la autonomía de los jóvenes, sea en el consumo de tiempo libre o en la tutela de su intimidad, con la posibilidad de tener cubiertas sus necesidades primarias mientras sigan quedándose en casa (Meil, 2011).

Los recursos disponibles en cada familia varían por cantidad y en función del tipo de ayuda (capitales económicos, patrimoniales, culturales y sociales) y del tipo de hogar (estructura, composición y ligámenes de parentesco) (Kohli et al., 2007). La decisión de abandonar el hogar depende del coste-oportunidad entre los recursos disponibles y el nivel de vida al cual el joven aspire. Por tanto, las preferencias individuales y las transiciones que se pueden desplegar de acuerdo con ellas, están muy relacionadas con la posición de la familia en la escala social (Requena, 2006).

En un sistema familista tradicional, el proceso de emancipación está orientado hacia la formación de un nuevo núcleo familiar, sin romper los ligámenes con el hogar de origen. Formar una familia es la razón principal de independencia para la mayoría de los jóvenes españoles, mientras que en los países de la Europa continental y nórdica los veinteañeros son más proclives a dejar la casa paterna por motivos de estudio o trabajo, o por el deseo de vivir solos (Moreno Mínguez y Gentile, 2011).

La transición de la familia de origen a la familia de destino se realiza una vez que el joven tiene adquiridas la estabilidad económica y laboral, la unión afectiva con una pareja, el vínculo del matrimonio y la seguridad de una vivienda, preferiblemente en régimen de propiedad (Iacovou, 2010). Estos elementos configuran "trayectorias de estabilidad» (Gaviria, 2007), todo lo que se escapa de este modelo no favorece la asunción de responsabilidades 
adultas de una forma socialmente deseable y esperable. El aplazamiento de la salida del hogar se explica por la falta de uno de estos aspectos, por las dificultades para consolidarlos y por el apoyo familiar para alcanzar el mejor encasamiento posible para los jóvenes. En particular, los padres tienden a incrementar su participación económica para proporcionar a los hijos aquel nivel educativo que les permita ocupar posiciones competitivas en el mercado de trabajo o por lo menos posiciones sociales equivalentes a las que ellos ya ocupan (Requena, 2006).

Con la crisis económica y con la intensificación de la dualidad en el mercado laboral entre insiders (trabajadores adultos, estables y tutelados) y outsiders (trabajadores jóvenes, flexibles y precarios) se debilita el canal de transmisión entre padres e hijos que permitía a los segundos heredar el mismo estatus social, la misma categoría profesional y posibilidad de mejora económica, así como el mismo nivel de bienestar que tuvieron los primeros (Gil Calvo, 2005; Casal et al., 2011).

Las clases medias sufren mayormente la desestructuración de estas correspondencias porque su subsistencia depende del mantenimiento de posiciones estables y cualificadas en el mercado laboral. Los jóvenes desprovistos de empleos seguros y de calidad ven quebradas sus expectativas de promoción personal y social. Las nuevas generaciones de clase media ven disminuir su bienestar y sus oportunidades profesionales, marcando una diferencia sustancial respecto al tipo de integración social que tuvieron los padres (Marí-Klose y Marí-Klose, 2006).

Desde antes de que empezara la coyuntura negativa actual la clase media española ha sufrido un endurecimiento de sus perspectivas de movilidad social ascendente (Tezanos, 2001). Esta tendencia se ha intensificado a partir de 2008, es decir, desde que se ha empezó a observar en nuestro país que los títulos educativos superiores no ponían siempre a salvo a los jóvenes de los riesgos de paro y de precariedad laboral (Gentile, 2013), mientras que las trayectorias de ascenso social de los jóvenes respecto a sus familias se iban estancando o quebrando en la cadena sucesoria entre generaciones (Moreno y Marí-Klose, 2013). En consecuencia, la vulnerabilidad del proceso emancipatorio de los jóvenes de clase media parece reflejarse en un progresivo debilitamiento de la posición social alcanzada por su familia y, más en general, por su estrato social de pertenencia. Conocer su punto de vista respecto a la crisis significa también saber más acerca de este fenómeno todavía en curso, por eso acudimos a los testimonios de jóvenes con titulaciones académicas. 


\section{JÓVENES TITULADOS SUPERIORES FRENTE A LA CRISIS: TRES PERSPECTIVAS INTERPRETATIVAS}

La crisis económica perjudica la participación de los jóvenes en el mercado de trabajo (Aragón et al., 2011). Su integración laboral está modulada por un alto grado de flexibilidad de entrada -funcional y numérica- con una mayor exposición a situaciones de temporalidad con respecto a la población adulta porque ocupan principalmente segmentos periféricos y secundarios del sistema productivo (Álvarez et al., 2013). En consecuencia, sus transiciones vitales son inseguras y frágiles.

En la última década la educación superior se ha extendido entre los jóvenes españoles como una opción estratégica muy importante para prepararse mejor en la búsqueda de un empleo significativo. Se consolida así un segmento de jóvenes que acuden a los estudios post-obligatorios, y en particular a la universidad, prolongando su etapa formativa a la vez que aplazan su entrada en el mundo del trabajo. Sin embargo, una vez acabados los estudios, la situación ocupacional de los titulados universitarios no mejora automáticamente, según sus expectativas. Prueba de ello es el sensible aumento del paro entre los jóvenes titulados superiores a partir de 2009 y la evidencia de una correspondencia incompleta e inadecuada entre su cualificación formal y su colocación laboral (Moreno Mínguez et al., 2012). La devaluación de los títulos académicos, especialmente de aquellos menos orientados a las prácticas profesionales, no favorece la estabilidad y tampoco la promoción de carreras ordenadas y coherentes (Ariño y Llopis, 2011).Además, nuestro sistema de empleo expulsa a los jóvenes que tienen un nivel de estudio bajo y posiciona los que disponen de una preparación académica en empleos que necesitan una formación inferior (Toharia et al., 2008).

En la actualidad nuestro sistema productivo no es receptivo para una mano de obra altamente titulada: el crecimiento económico se ha estancado, el sector público de servicios ha comenzado una profunda reestructuración a partir del adelgazamiento y del desmantelamiento de sus plantillas, y la inversión en innovación y en sectores avanzados es netamente inferior a la que se registra en los demás países europeos. Según datos de la OCDE, desde finales de los años noventa el gasto en I+D ha registrado una tendencia ascendente en España que se ha truncado con la recesión económica. En 2009 se produjeron reducciones significativas del crédito presupuestario en este ámbito con un recorte de 580 millones de euros, al cual se ha añadido otro recorte de 533 millones en 2010, situándolo en un 1,39\% del 
PIB, el mismo porcentaje que un año antes y lejos del promedio del $2 \%$ de la Unión Europea.

Si comparamos la situación de los titulados superiores españoles con sus pares de edad en el resto de Europa, los universitarios españoles pasan por periodos más largos para estabilizar sus carreras profesionales (Eurostat, 2009), tienen mayores probabilidades de desempeñar trabajos que no se corresponden con sus cualificaciones y su ventaja salarial respecto a los graduados de secundaria es comparativamente inferior. Según el informe Education at a glance 2008 (OCDE) un titulado universitario de entre 25 y 64 años en España percibe en promedio un 32\% más que otro con un nivel de titulación inmediatamente inferior, con independencia del tipo de estudios académicos cursados. Desde 1997 hasta 2006 observamos una disminución del $17 \%$ de esta ventaja entre un graduado en enseñanza académica y un graduado con educación secundaria. Este agravio comparativo de los titulados superiores en términos salariales y de estabilidad ocupacional se ha mantenido en España también entre 2008 y 2010 (Gentile, 2013).

Rentabilizar las inversiones formativas realizadas no es fácil para nuestros jóvenes titulados superiores. En consecuencia, peligran también sus transiciones a la vida adulta. Los universitarios que proceden de familias de clase media se sienten especialmente defraudados por el sistema de enseñanza respecto a sus preferencias de inserción laboral (Langa, 2005; Ariño y Llopis, 2011).

Es plausible creer que este juicio haya empeorado en los últimos años. Por eso, hemos querido investigar los humores y las opiniones de quienes ha finalizado la universidad con éxito y enseguida se han enfrentado a un mercado de trabajo muy poco halagüeño.

A continuación detallamos tres discursos que nos permiten destacar sus posiciones frente a la crisis, especificando las estrategias de independencia que plantean y sus posibilidades de realizarlas.

\subsection{La crisis como trampa}

Todos los entrevistados consideran que la precariedad es la condición que comparte la mayoría de sus coetáneos hoy en día. En particular, siete de ellos reconocen que la crisis está desestructurando sus pautas de emancipación. Son entrevistados procedentes de familias de clase social mediobaja, insatisfechos por su situación laboral y cansados por la prolongada e involuntaria permanencia en casa de los padres. 
Los estudios universitarios han sido opciones ponderadas para encontrar un buen posicionamiento en el mercado de trabajo. Sin embargo, nada más acabar sus carreras, se han encontrado con el empeoramiento de la economía nacional y con mayores dificultades para encontrar y mantener un empleo. En las experiencias de trabajo que han tenido recientemente no se han sentido valorados por sus titulaciones tal como se esperaban. Es este el caso de unos licenciados en Ciencias humanas y sociales que no están contentos con sus trabajos ocasionales o sin contratos y de aquellos informáticos e ingenieros que trabajan con contratos por obra y servicio desempeñando tareas que no corresponden a sus reales competencias.

Acabas la carrera, luego te quedas en paro o haciendo algo precario, que te sienta fatal. Eso es lo que hay... no podía preverlo cuando estaba en la universidad. Mi idea era estudio, el curro, trabajo en algo de verdad y me voy de casa. Lo de siempre, lo normal (Ent. 4).

Haber pasado por diferentes trabajos de corta duración, a menudo cambiando de un sector a otro (incluso en los sectores menos cualificados como hostelería y servicios de cuidado para niños), no les permite desarrollar una carrera profesional significativa. Por eso, replantear a la baja sus expectativas laborales es algo que ellos consideran inevitable y nada confortable:

Una carrera es algo que tiene valor, es siempre un título ¿no? Con el tiempo me he dado cuenta que no siempre te sirve para algo [...]. Tienes que trabajar para comer, hay que coger los trabajos que se ofrecen, por muy malos que sean, ya que si no, los van a coger otros. (Ent. 15).

No disponen de canales adecuados para encontrar trabajo o para rentabilizar su titulación, suelen acudir a sus redes familiares y de amigos para enterarse de las ofertas de empleo existentes.

Emprender ulteriores especializaciones, cursos de formación o posgrados representa una estrategia que ellos valoran positivamente. Continúan estudiando "para hacer algo, por lo menos dices: no estoy perdiendo el tiempo» (Ent. 4), "para acumular experiencias y acumular títulos» (Ent. 12), sin la garantía de una salida inmediata y definitiva, al contrario, con la sensación de que estas opciones puedan acentuar su frustración en lugar de resolverla.

No se sienten integrados plenamente en el mercado de trabajo y, en consecuencia, tampoco en la sociedad. La fragilidad de su transición formativa-laboral tiene repercusiones sobre el resto de sus proyectos personales Por eso, consideran que tener un empleo estable es la condición mínima 
y necesaria para construir una vida por cuenta propia y para constituir un nuevo hogar.

Señalan su escasa disponibilidad salarial como mayor impedimento para sus opciones de independencia. No tienen la garantía de una renta de trabajo estable y tampoco disponen de suficientes ahorros para pagarse una vivienda, en alquiler o de propiedad, considerando los precios elevados de servicios y pisos en Madrid capital. Les resulta complicado hacer frente a gastos imprevistos y en ningún caso ven practicable la creación y el mantenimiento de una familia.

Aplazar la salida del hogar es la única solución posible ahora, pero no quieren abusar de sus familias demorando su estancia en el hogar a tiempo indefinido porque ya han contado con su apoyo material y logístico durante los años de la universidad.Además, ellos entienden que sus padres pueden cubrir sus necesidades solo de forma parcial y limitada:

Mis padres ya tienen la hipoteca, mi hermanito y tal... si me marchara de casa incluso podría hacerles un favor [...]. Mis padres no me han hecho faltar nunca nada, me lo han dado todo, y eso que no somos una familia rica... Ellos no pueden hacerse cargo de mi precariedad (Ent. 20).

Para estos entrevistados el umbral de los 30 años marca simbólica e inexorablemente el retraso del paso definitivo a la vida adulta. Cuanto más se acerca esta edad tanto más se sienten presionados por «el tiempo que pasa». Se trata de una preocupación que contribuye a aumentar las tensiones con los padres en casa, como resultado de un cúmulo de ansiedad y de nerviosismo que crece cada día:

Ahora la situación es difícil. Mis padres saben que estoy al límite, a veces les contesto mal, estoy nerviosa porque no veo futuro... esa no es mi casa ¿entiendes? No es lo que quiero para mi... y ellos están nerviosos porque me ven nerviosa, es una cadena (Ent. 11).

Estos entrevistados recuerdan que sus padres, cuando tenían su edad, contaban con un trabajo estable, con salarios mejores o por lo menos suficientes para comprarse una vivienda y sustentar un núcleo familiar. Se comparan así los modelos convencionales de emancipación con las transiciones incompletas o incumplidas que ellos están experimentando ahora en contra de su voluntad.

Al margen de sus diferencias personales, los jóvenes que describen la crisis como una trampa no se sienten dueños de sus destinos y echan en falta sus puntos de referencia para planificar los pasos a seguir, convencidos de que sus transiciones ya no se pueden desarrollar tal como hicieron sus 
padres. Las cosas han cambiado y saben aguantar este cambio solamente viviendo al día, sin ofrecer una respuesta clara sobre su próximo futuro.

No hay una verdadera reacción por su parte sino una aceptación resignada de la realidad. Sintetizan su estancamiento en dos fórmulas: «quiero pero no puedo» y además «tampoco sé cómo podría». Se dan cuenta que los caminos que pasan por el trabajo y que deben llevarlos a ser plenamente emancipados les están vetados.

Eres adulto cuando las cosas van bien, cuando tienes trabajo, tienes todo... cuando tienes una familia ya te consideras como un adulto [...] yo no tengo esas cosas, no soy adulto, es que así estoy... no sé cuándo cambiará esto (Ent. 12).

Se sienten defraudados respecto a aquellas expectativas que han madurado en el seno de sus familias y que se caracterizaban por pautas preestablecidas de emancipación. La flexibilidad no es sinónimo de oportunidad sino causa y efecto de transiciones fallidas: la precariedad laboral se manifiesta en sus vidas como precariedad existencial.

Las familias representan, en su opinión, las únicas fuentes disponibles de solidaridad y apoyo. Gracias al soporte que les brindan sus padres, consiguen mantener un cierto pragmatismo minimalista y defensivo, limitándose a lo que ya tienen asegurado en el hogar. Fuera de allí, sus transiciones parecen desligadas de cualquier proyecto profesional o personal a largo plazo. Quedan así suspendidos en un limbo donde se sienten víctimas de las circunstancias y espectadores pasivos del desmoronamiento de sus esperanzas.

\subsection{La crisis como obstáculo}

Ocho de nuestros entrevistados reconocen la gravedad de la coyuntura económica pero se declaran optimistas porque están involucrados en proyectos de emancipación coherentes con sus itinerarios formativos. Para ellos, tener un empleo de calidad es una condición imprescindible para ser adultos. Su prioridad es entonces utilizar el título y las competencias adquiridas en la universidad para construirse carreras profesionales que les permitan conseguir una inserción social completa y positiva. La estabilidad y la autorrealización son metas que quieren lograr esforzándose, con un compromiso personal fuerte y gracias al respaldo constante e incondicional de sus familias: 
Mis padres cuidan de mí, es una suerte, aun más con esta crisis [...]. Siempre he tenido las ideas claras, creo que así se supera la crisis, si quieres... es difícil, uno lo intenta, a ver qué pasa... este es el espíritu, bueno esto es mi espíritu, y mis padres están conmigo (Ent. 2).

Las consecuencias de la crisis no pasan desapercibidas, pero las gestionan en el hogar y desde el hogar: los lazos inter-personales e inter-generacionales en la familia configuran una red de referencia fundamental para evitar los riesgos a los cuales podrían exponerse si estuvieran fuera de casa. Reconocen que sus condiciones familiares de partida son favorables para no caer en la trampa de la precariedad. Sus padres tienen empleos estables, buenas condiciones económicas y, según cuanto nos comentan, están volcados en apoyarles para que ellos construyan su futuro rentabilizando el nivel de estudio alcanzado.

El apoyo a los hijos es generoso, se configura como inversión de largo plazo y se asocia a una ética de extensa autonomía para que "construya $m i$ camino yo sola» (Ent. 2) o «encuentre algo bueno, algo que sea acorde con mis estudios» (Ent. 19). La intención de estos jóvenes es quedarse en casa hasta que consigan obtener una cierta continuidad laboral y los recursos suficientes para emanciparse. De esta manera, pueden ahorrar dinero, emprender cursos de especialización o aceptar empleos en prácticas para acumular experiencia; para planificar su independencia sin apuros.

Continuar formándose significa enriquecer el bagaje de conocimientos y competencias para luego distinguirse en un determinado ámbito profesional y contar con trayectorias laborales coherentes y congruentes con sus estudios. Este planteamiento es manifiesto en el discurso de una joven psicóloga que acaba de tener sus primeros encargos de responsabilidad en una consultoría, de dos titulados en derecho que colaboran con gabinetes de abogados, y de otro licenciado en economía y que trabaja por obra y servicio en una empresa. Sus condiciones laborales no son satisfactorias desde un punto de vista salarial, sin embargo reconocen que lo que están aprendiendo les valdrá para poder ocupar un puesto mejor pronto. La precariedad es un trámite además de una prueba para testar la consistencia de sus trayectorias:

Es frustrante, pero yo me lo planteo como algo temporal, es decir si hubiera sido precario mucho tiempo, estaría en casa llorando... me sigo viendo como una persona que se está formando, cada trabajo es complementario a mi formación, no lo veo todo negativo, es un trámite (Ent. 17).

Las entrevistadas que comparten este discurso señalan el mayor esfuerzo para cumplir con su transición formativa y laboral respecto a sus coetá- 
neos en un mercado de trabajo que, en su opinión, les excluye a priori por ser mujeres y jóvenes. En este sentido, los méritos que ellas pueden ganar aplicándose en los estudios o aprovechando los títulos que han conseguido les permiten evitar discriminaciones sexistas. Cabe subrayar que las desigualdades de género en España son patentes entre los graduados universitarios por lo que se refiere a la existencia de una brecha salarial y de una posibilidad relativa menor de ocupar posiciones de liderazgo en el mercado de trabajo. Según la Encuesta Anual de Estructura Salarial del INE de 2012 el salario medio anual femenino representa el $76,1 \%$ del masculino. Según la última Encuesta de Estructura Salarial que el INE realiza cada cuatro años, en 2010 esta brecha es igual al $24,7 \%$ entre los diplomados universitarios y al 30,3\% entre los licenciados, ingenieros superiores y doctores. Acceder a un empleo acorde con su titulación, significa para nuestras entrevistadas no solo monetizar la inversión en los estudios sino también reivindicar una efectiva igualdad de oportunidades en términos profesionales ${ }^{3}$.

Ellas, de acuerdo con los demás entrevistados que comparten su punto de vista, pretenden salvaguardar un cierto bienestar (nivel de consumo y estilo de vida) y mejorar progresivamente respecto a sus situaciones de partida. Se trata de una lógica selectiva y corporativa porque la identidad social, así como la forma de ser y de llegar a la edad adulta, depende de su acceso y pertenencia a una determinada categoría profesional. Para emanciparse en tiempos de crisis es necesario entonces hacer coincidir la estabilidad ocupacional con una carrera profesional sólida.

La salida del hogar, la adquisición de una vivienda y la constitución de una familia son etapas consecuentes y condicionadas a estos objetivos de inserción laboral. La misma relación de pareja queda afectada por una lógica que privilegia el empleo como condición ineludible para reivindicar una autonomía propia.

No quiero que mi novio me mantenga, en la pareja cada uno trabaja en lo suyo, luego estamos juntos, compartimos algo, lo ponemos en común, cada uno con su trabajo, con sus cosas (Ent. 16).

La prioridad de un empleo seguro está reconocida también por aquellos entrevistados que proceden de dos familias situadas en posiciones distintas de la escala social. Respecto a esto, nos encontramos con dos chicos, ami-

3 Según datos de la Comisión Europea, en 2013 el porcentaje de mujeres en los Consejos de Administración de los Organismos Públicos y Empresariales en España es 14,8\% mientras que en los Consejos de Administración de las Empresas del IBEX-35 es 8,7\%. En ambos casos estamos lejos de los objetivos fijados por la Unión Europea. 
gos entre sí (uno de clase medio-alta con padres licenciados y funcionarios, y otro de clase medio-baja, su padre es un pequeño comerciante y la madre ama de casa) que se licenciaron en derecho y que ahora están preparando una oposición para la administración pública:

Apostamos por lo mismo, te sacas la oposición y tienes resuelta tu vida [...] este año la reducción de las plazas ha sido brutal, y para nosotros que llevamos estudiando y esperando, pues ha sido una putada... te preparas los temas, eso es también un gasto para nosotros, una inversión (Ent. 8).

Su transición a la vida adulta se corresponde con una inversión de tiempo, dinero y dedicación para resolver la propia inserción laboral de forma definitiva y óptima. La crisis es un obstáculo pero no les supone un replanteamiento del camino a seguir, sino más bien les proporciona unas pruebas en el itinerario de emancipación que han elegido y que quieren seguir desarrollando.

La crisis ha sido un parón para todos, lo veo también entre mis amigos, las cosas están muy mal, quien se salva de la crisis lo tendrá todo más fácil, yo lo intento, no tiro la toalla (Ent. 19).

Ellos asumen una postura activa y ambiciosa, además de paciente. Cualquier estrategia de transición se reconduce a una toma de decisiones que conjuga la racionalidad de coste-oportunidad con una practicidad que tenga efectos previsibles, ventajosos y duraderos. Mientras tanto, salir de casa en las condiciones laborales en las que se encuentran, con contratos temporales y salarios bajos, es una opción poco conveniente y potencialmente lesiva, porque podría poner en entredicho los itinerarios que han realizado hasta la fecha, e incluso hacerles perder los beneficios esperados.

Sus aspiraciones confluyen en un proyecto ordenado de estabilidad (laboral), prestigio (profesional) y propiedad (de una casa). Los efectos de la crisis no llegan a ser percibidos como peligros reales hasta que no esté alterada esta secuencia de prioridades.

La transición a la vida adulta implica una evolución individual buscando cualquier oportunidad de mejora que pueda favorecerles en la construcción de su proyecto biográfico. No hay tiempo para distraerse, no es aceptable despilfarrar los esfuerzos realizados hasta la fecha, tampoco es posible renegar las metas y las aspiraciones que consideran a su alcance. Cada uno tiene que resolver la crisis confiando en sí mismo, en sus medios y en el apoyo que los padres pueden proporcionarles. En esa carrera de obstáculos saldrá mejor quien supere todas las pruebas para llegar a ser adulto. 


\subsection{La crisis como oportunidad}

Cinco entrevistados formulan un discurso sobre su transición a la vida adulta en tiempos de crisis que se diferencia de las posturas que hemos presentado hasta ahora. Son titulados superiores que proceden de familias con una alta disponibilidad económica y patrimonial, viven al amparo de sus padres y construyen sus proyectos de emancipación desde una posición social de ventaja objetiva.

«Mis padres son mi seguridad social. Eso me hace estar tranquilo [...] la crisis es chunga pero si no fuera por ellos... estoy en una posición mejor que otros, esto me hace pensar positivo (Ent. 9).

En sus testimonios hacen hincapié en la posibilidad de aprovechar la inestabilidad estructural en la que nos encontramos. Su lógica se fundamenta en la búsqueda de soluciones personalizadas para adaptarse a los cambios del entorno socio-económico. Ellos mismos subrayan su capacidad de moverse en el umbral de una «incertidumbre continua», asumiendo voluntariamente la flexibilidad como estilo de vida que caracteriza distintos ámbitos de su emancipación.

Los entrevistados que asumen esta perspectiva alternan estudio y trabajo o desempeñan una variedad de colaboraciones laborales de corta duración. En sus transiciones buscan siempre beneficios tangibles, inmediatos, con una actitud experimental, curiosa y abierta al cambio. No les preocupa tener trayectorias profesionales acordes con los estudios; prefieren defender sus deseos y vocaciones y reivindicar sus prerrogativas para ser felices sin dejarse presionar por la crisis:

Lo enfoco cómo ser feliz día a día. Con las pequeñas cosas de la vida y no aspirar a grandes cosas. Levantarme, y si no puedo ir a cenar a un restaurante carísimo pues, voy a uno más baratito. Sin renunciar a las cosas importantes, disfrutar del día a día (Ent. 3).

Estos participantes adecuan sus itinerarios sin dejarse bloquear o desanimar por la inseguridad del contexto actual. Insisten en su constante propensión a la movilidad geográfica, es decir viajar, conocer nuevas realidades y ampliar sus experiencias. Sus transiciones residenciales se caracterizan por una reversibilidad frecuente, con salidas y vueltas intermitentes al hogar familiar. El ocio y el consumo son una constante para ellos, independientemente de su situación laboral. Tales aspectos contribuyen a la amplia heterogeneidad y complejidad de sus historias, diferenciándose de 
los demás entrevistados cuyos itinerarios de emancipación son más lineales y secuenciales.

La imprevisibilidad de sus transiciones es un activo para buscar alternativas capaces de reforzar su autonomía y distinguirse respecto a los demás. Aunque reconocen la intervención de los padres como apoyo estratégico irrenunciable, se sienten únicos y verdaderos responsables de sus vidas. Estos entrevistados trabajan para costearse sus consumos cotidianos y se gastan el dinero sin preocuparse del futuro. No están orientados hacia pautas preestablecidas de emancipación, porque ya no las ven compatibles con sus expectativas:

\footnotetext{
Vivimos en tiempos diferentes, hace veinte años la gente se echaba novia, por así decirlo, y en cuatro días pues se casaban y empezaban a formar una familia [...] antes la gente solía tener un trabajo para toda la vida, ahora lo que se está imponiendo es estar trabajando en un sitio, mañana en otro sitio, pasado mañana en otro ęentiendes? Buscas algo que te gusta, si sale bien, si no cambias, y sigues así... te haces tus experiencias, no piensas en montarte una familia (Ent. 10).
}

Saben que existen todavía unos modelos convencionales de transición a la vida adulta, pero no se sienten obligados a seguirlos. Al contrario, otorgan nuevos significados a sus opciones de emancipación: consideran que su situación actual se configura como una etapa distinta del ciclo vital, más que como una fase de mera transición, en la que puede expresarse según la volatilidad de sus antojos. De hecho, estos cinco entrevistados coinciden en una idea de «ser adultos» que se aleja de los «cánones tradicionales», por ejemplo, considerando positivamente la convivencia entre amigos o la cohabitación entre parejas, y no les supone ningún problema dejar un trabajo para tomarse un año sabático, viajar, o dedicarse a la música, al deporte, siempre en búsqueda de nuevos horizontes.

No haber cumplido o superado los 30 años de edad les permite explicar su voluntad de «buscar nuevas oportunidades para crecer como persona» (Ent. 9), "bacer tu vida sin dejar que el curro te lo estropee todo» (Ent. 3). Esta búsqueda es sinónimo de asunción de un espacio propio y distintivo en la sociedad. La condición adulta no depende de un único episodio concreto (tener un empleo, salir de casa o casarse) porque se plantea como un proceso en continua re-definición, donde el empleo es un componente importante, claramente instrumental, pero no determinante.

Son conscientes de la posibilidad de encontrarse en una coyuntura problemática y se preocupan por conciliar su índole propositiva y creativa con un mínimo de sentido práctico. Esta visión les permite no vivir la precariedad como resistencia a su movilidad social o como debilitamiento de su 
bienestar material. La inestabilidad estructural no es entonces un obstáculo, sino más bien un entorno en el cual hace falta aprender a buscar nuevas oportunidades, cada uno según sus posibilidades y aspiraciones.

Exaltan su autonomía invirtiendo compromiso y entusiasmo en el presente despreocupándose por el futuro. Afirman que «tomar las riendas de tu vida» es algo inevitable y que pueden sostener: quien no comparte esta perspectiva pierde su tiempo, se queda pasivo ante la crisis, y por ello, en opinión de estos entrevistados, su posición es objeto de estigmatización y de crítica.

Quienes comparten esta visión confían en dejar el hogar hasta que esté garantizado un marco de tutelas básicas por parte de las instituciones públicas. Aun así, no expresan particular confianza en los decisores políticos: les piden más y mejores oportunidades para no sufrir los efectos de la crisis en términos de exclusión y para no sentirse limitados en sus estrategias de autorrealización.

No quieren resignarse a la precariedad, pero la estabilidad no es urgente y tampoco representa un ideal a perseguir: quieren estar capacitados para moverse en el entramado de riesgos que configuran su contexto de emancipación y aprovechar todo los que les pueda resultar conveniente e interesante.

Cuanto más desatendidas les resulten estas peticiones, más lógico ven buscar soluciones por cuenta propia. Aceptan estos riesgos como retos personales. No importa recalibrar sus vidas, porque quieren decidir cómo sostenerlas y desempeñarlas: cada uno está llamado a buscar su salida en la crisis pero antes es necesario aceptar los desafíos que esta supone.

\section{PRIVACIÓN RELATIVA E INDIVIDUALIZACIÓN DEL RIESGO}

Todos los participantes de este estudio reconocen que la situación económica de España no les es indiferente. El proceso de emancipación que están realizando se define en este contexto, por tanto su transición a la vida adulta se expone inevitablemente a la inestabilidad estructural.

A partir de aquí es interesante destacar las diferentes perspectivas de nuestros entrevistados sobre su forma de enfrentarse a la crisis actual. Los argumentos utilizados para justificar su permanencia en casa de los padres están conectados con distintas representaciones de esta coyuntura y, por ende, con las valoraciones personales de sus itinerarios recorridos y de los 
que les quedan por recorrer. Hemos resumido sus relatos en tres posicionamientos discursivos.

La crisis como trampa es la expresión elocuente de la precariedad laboral que determina una condición de precariedad vital. Se evidencia un malestar intenso que condiciona a estos jóvenes en la posibilidad de mantener una cierta seguridad y estabilidad tanto en el presente como en el futuro. Su frustración depende de la dificultad de completar los itinerarios de emancipación que han aprendido por costumbre y por tradición de su familia y a lo largo de sus experiencias personales. Creen que su conducta es la correcta y la legítima, ya que está encaminada por el itinerario formativo realizado. Acabar la educación superior les supone haber madurado una serie de expectativas que ahora no pueden ni saben cómo realizar. Su decepción se origina de la asimetría entre los estudios cursados y las efectivas oportunidades de inserción laboral a su alcance.

La comparación con las generaciones anteriores es indicativa de la privación que estos jóvenes están viviendo en relación con los caminos recorridos por sus padres. Según ellos, sus transiciones deberían desembocar en la formación de nuevas familias o caracterizarse por trayectorias irreversibles, sostenibles desde un punto de vista práctico $\mathrm{y}$, preferiblemente, en grado de garantizarles el mismo nivel de bienestar que disfrutarían si se quedaran en casa.

La desilusión es evidente porque sus condiciones ocupacionales son insatisfactorias y porque las posiciones de partida, en el hogar paterno, así como las expectativas de bienestar y de promoción social, son cada vez más difíciles de mantener. En tales circunstancias el replanteamiento de sus estrategias es considerado desmoralizante, además de inesperado e injusto. Los padres ayudan a los hijos de manera determinante porque entienden que de esta manera es posible garantizar la continuidad familiar y social. Siguiendo esta lógica, la capacidad de hacer frente a la crisis es un asunto clave para las estrategias sucesorias de cada hogar.

La frustración del joven en su emancipación puede convertirse, entonces, en la frustración de los padres a la hora de ver quebradas sus posibilidades de inserción y de realización personal.

En este último punto se fundamenta también el planteamiento discursivo de aquellos otros entrevistados que planifican su proyecto biográfico a partir de transiciones pautadas y vinculadas a la inserción laboral, ya que la transición residencial es secundaria a su estabilidad en el mercado de trabajo. Para realizar esta trayectoria ellos persiguen una salida profesional congruente con los estudios realizados. La familia representa un soporte 
fundamental en cada momento para mantener esta coherencia y superar todos los obstáculos que la crisis les va suponiendo.

Nuestros participantes reclaman el derecho de poder rentabilizar el propio título de estudio: cuanto más logran aumentar el mérito adquirido en su itinerario académico tanto más ven reforzada la legitimidad de sus peticiones. Cabe preguntarse hasta cuándo podrán defender esta estrategia, considerando que su mismo desenlace depende de los recursos económicos y sociales que estos jóvenes tengan a su disposición en cada hogar.

Finalmente, destacamos una tercera perspectiva entre aquellos entrevistados que declaran asumir sin particulares apuros los riesgos sociales adscritos a la crisis. Una vez más, se denuncia cómo se han multiplicado los problemas de los jóvenes españoles para ser autónomos e independientes en esta coyuntura económica. Sin embargo, entre estos participantes se detecta una asunción consciente de la inestabilidad y una adaptación a la misma sin renunciar a las propias prerrogativas. La transición a la vida adulta ya no es solamente un conjunto de itinerarios fijos y preestablecidos, sino más bien un proyecto individual dinámico. Estamos hablando de un recorrido biográfico que se redefine continuamente y cambia según las circunstancias y según las variables perspectivas de cada joven. Reivindicar un lugar en la sociedad significa hacer lo posible para evitar que la crisis altere el rumbo de los intereses, de las vocaciones y de las exigencias individuales. Por eso, la inestabilidad invita a estos entrevistados a activarse para buscar sus soluciones, encontrar oportunidades nuevas, caminos alternativos y, eventualmente, originales que ellos mismos elijan perseguir.

En su opinión, la posibilidad de contar con los recursos de los padres es meramente instrumental, de subsistencia básica, y no los emplean para conseguir transiciones definitivas en el mundo del trabajo o para formar una familia. Las experiencias son enriquecedoras en la medida en que son muchas y son coherentes con la satisfacción inmediata de las propias exigencias. Esta perspectiva otorga sentido a unas relaciones de pareja más fluidas, sin considerar necesariamente una perspectiva de vida en común, a la vez que se explica por unas estrategias residenciales contingentes y flexibles, más que referidas a la permanencia en un único hogar. La estabilidad no es prioritaria.

A cada perspectiva discursiva para definir el posicionamiento frente a la crisis le corresponde una distinta capacidad negociadora del joven con su familia. Los padres pueden atenuar el agobio de la trampa en la que se encuentran algunos entrevistados, pero pueden también fomentar sus capacidades de reacción, reforzando o vinculando planes de emancipación 
orientados a superar los obstáculos de la crisis o a secundar la inestabilidad de forma ventajosa y propositiva.

En todos los casos, la fragmentación de las transiciones a la vida adulta es muy compleja porque se acentúan las diversidades adscritas individual y socialmente. Observando los efectos de la crisis en las vivencias de los jóvenes que hemos entrevistado podemos vislumbrar un escenario de cambio social: por un lado, los proyectos de emancipación están cada vez más volcados hacia nuevas formas de plantear y desarrollar las transiciones a la vida adulta; por otro, este cambio coincide con el aumento de las desigualdades entre aquellos que logran salir de la coyuntura actual más fuertes o más débiles que antes.

\section{BIBLIOGRAFÍA}

Álvarez, C.; Davia Rodríguez, M.A. y Legazpe, N. (2013). «Impacto laboral de la crisis económica: Privación de empleo y precariedad», Papeles de Economía Española, 135, pp.83-98.

Aragón, J.;A. Martínez;J. Cruces y F. Rocha SÁnChez (2011): Las políticas de empleo para jóvenes en España. Una aproximación territorial, Colección Informes y Estudios 22, Madrid, Ministerio de Trabajo e Inmigración.

ARIÑO, A. y R. LlopIs (2011): ¿Universidad sin clases? Condiciones de vida de los estudiantes universitarios en España, Madrid, Ministerio de Educación.

Casal, J.; Merino, R. y M. García (2011): «Pasado y futuro del estudio sobre la transición de los jóvenes», Papers. Revista de Sociología, 96(4), pp.11391162.

Conde Gutiérrez, F. (2009): Análisis sociológico del sistema de discursos, Cuadernos Metodológicos, 43, Madrid, Centro de Investigaciones Sociológicas.

Eurostat (2009): Youth in Europe. A Statstical Portrait, Luxembourg: Publications Office of the European Union.

FLAQUER, L. (2004): «La articulación entre familia y el Estado de Bienestar en los países de la Europa del sur», Papers. Revista de Sociología, 73, pp.27-58.

GaVIRIA, S. (2007): Juventud y familia en Francia y en España, 234, Madrid, Centro de Investigaciones Sociológicas.

Gentile,A. (2013): Emancipación juvenil en tiempos de crisis. Un diagnóstico para impulsar la inserción laboral y la transición residencial, Estudio 73, Madrid, Fundación Alternativas. 
GIL Calvo, E. (2005): «El envejecimiento de la juventud», Revista de Estudios de Juventud, 71, pp.11-19.

IAcovou, M. (2010): «Leaving home: Independence, togetherness and income», Advances in Life Course Research, 15, pp.147-160.

INE (Instituto Nacional de Estadística) (2012): Encuesta Anual de Estructura Salarial. www.ine.es - (2010): Encuesta Cuatrienal de Estructura Salarial. Www.ine.es

Kohli, M.; M.Albertini y C.Vogel (2007): «Intergenerational transfers of time and money in European families: common patterns - different regimes?», Journal of European Social Policy, 17, pp.319-334.

LANGA RosADO, D. (2005): «La juventud de los universitarios construida desde distintas posiciones de clase. Nuevas manifestaciones de las desigualdades en el campo educativo», Revista Española de Sociología, 5, pp.7190.

López Blasco,A. (2005): «La familia como respuesta a las demandas de individualización: ambivalencias y contradicciones», Papers. Revista de Sociología, 79, pp.263-284.

Marí-Klose P. y M. Marí-Klose (2006): Edad del cambio. Jóvenes en los circuitos de solidaridad intergeneracional, 226, Madrid, Centro de Investigaciones Sociológicas.

Moreno, L. y Marí-Klose, P. (2013): «Youth, Family Change and Welfare Arrangements. Is the South still so Different?», European Societies, 15(4), pp.493-513.

MeIL, G. (2011): Individualización y solidaridad familiar, Colección Estudios Sociales 32, Barcelona, Fundación La Caixa.

Moreno Mínguez, A.; López Peláez, A. y S. Segado Sánchez (2012): La transiciones de los jóvenes españoles en un contexto de crisis económica, Colección Estudios Sociales 34, Barcelona, Fundación La Caixa.

Msssi (Ministerio de Sanidad, Servicios Sociales e Igualdad) (2013): Análisis de la situación actual de las mujeres consejeras en España, Gobierno de España, Madrid, http://www.objetivo15.net/mujeresenconsejos.html ocde (Organización para la Cooperación y el Desarrollo Económicos) (2009): Education at a Glance 2008: OECD Indicators. www.oecd.org

Moreno Mínguez,A. y A. Gentile (2011), «I giovani-adulti spagnoli tra lavoro e famiglia. Conciliazione ed emancipazione in una prospettiva comparata e di genere», Rivista delle Politiche Sociali, 3/2011, pp.251-270.

Requena, M. (2006): «Familia, convivencia y dependencia entres los jóvenes españoles». Panorama Social, 3, pp.64-77. 
Tezanos, J. F. (2001): La sociedad dividida. Estructuras de clases y desigualdades en las sociedades tecnológicas, Madrid, Biblioteca Nueva.

Toharia, L. C., Davia Rodríguez, M.A. y C. Verdú (2008), «To find or not to find a first significant job», Revista de Economía Aplicada, 16(46), pp.37-60.

\section{APÉNDICE}

Las entrevistas han sido realizadas entre abril y septiembre de 2011 a doce hombres y a ocho mujeres de entre 24 y 30 años, todos graduados y licenciados universitarios. Los participantes han sido contactados utilizando la técnica «bola de nieve»: cada entrevistado nos ha referido los nombres de otros compañeros desarrollando una progresión y multiplicidad de otras personas susceptibles de ser entrevistadas. La elección de nuestros participantes ha sido realizada en función de la clase social de sus padres, distinguiendo entre:

Jóvenes procedentes de familias de clase medio-baja:

- título de estudio de los padres: sin estudios / primarias / bachillerato;

- ocupación de los padres: asalariados por cuenta ajena, trabajadores manuales de industria y servicios, pequeños comerciantes;

- vivienda: pagando hipoteca, casa de protección oficial, alquiler, sin otras casas en propiedad.

Jóvenes procedentes de familias de clase medio-alta:

- título de estudio de los padres: licenciados / titulados superiores;

- ocupación de los padres: profesionales, empresarios, funcionarios;

- vivienda: casa en propiedad (donde residen), con otras casas en propiedad. 


\begin{tabular}{|c|c|c|c|}
\hline ENTREVISTA & EDAD & SITUACIÓN ACTUAL & $\begin{array}{r}\text { CLASE } \\
\text { SOCIAL }\end{array}$ \\
\hline \multicolumn{4}{|c|}{ CRISIS COMO TRAMPA } \\
\hline 1. Hombre & 25 & $\begin{array}{l}\text { Graduado en ciencias políticas. Ha trabajado } \\
\text { como administrativo, ahora trabaja en una } \\
\text { tienda. Viven con los padres, comerciantes, } y \\
\text { con el hermano menor. }\end{array}$ & MB \\
\hline 4. Hombre & 27 & $\begin{array}{l}\text { Licenciado en ingeniería, está haciendo un } \\
\text { curso de informática.Trabaja como tele-opera- } \\
\text { dor. Vive con los padres y el hermano menor. } \\
\text { Su padre está jubilado y la madre es ama de } \\
\text { casa, otra hermana mayor está casada. }\end{array}$ & MB \\
\hline 11. Mujer & 27 & $\begin{array}{l}\text { Licenciada en antropología.Trabaja en un cen- } \\
\text { tro de servicios, se le acaba el contrato en un } \\
\text { mes. Vive con la madre, viuda, y con una her- } \\
\text { mana menor que es monitora de colegio. }\end{array}$ & MB \\
\hline 12. Hombre & 28 & $\begin{array}{l}\text { Licenciado en informática. Después de un pe- } \\
\text { riodo de desempleo ha empezado a diseñar } \\
\text { páginas web como autónomo. Los encargos } \\
\text { han ido disminuyendo en los últimos meses y } \\
\text { no sabe si continuará.Vive con la madre, divor- } \\
\text { ciada y sin trabajo, y dos hermanas pequeñas. }\end{array}$ & MB \\
\hline 15. Hombre & 28 & $\begin{array}{l}\text { Licenciado en psicología. Ha hecho muchos } \\
\text { trabajos, todos precarios, para ser autosufi- } \\
\text { ciente y para ayudar sus padres con el pago } \\
\text { de la hipoteca. Ahora está en paro, volverá a } \\
\text { trabajar en un hotel durante el verano. Quiere } \\
\text { ahorrar dinero para salir de casa, no excluye el } \\
\text { poder irse al extranjero. }\end{array}$ & MB \\
\hline 18. Mujer & 28 & $\begin{array}{l}\text { Licenciada en magisterio. Hasta hace poco ha } \\
\text { sido monitora de colegio. Quería preparar una } \\
\text { oposición para ser funcionaria pero aún no ha } \\
\text { empezado a estudiar.Trabaja en un bar con el } \\
\text { novio. Después del verano empezará un curso } \\
\text { de auxiliar administrativo. Vive con la madre, } \\
\text { maestra de instituto, y con una hermana, es- } \\
\text { tudiante. }\end{array}$ & MB \\
\hline
\end{tabular}




\begin{tabular}{|c|c|c|c|}
\hline ENTREVISTA & EDAD & SITUACIÓN ACTUAL & $\begin{array}{r}\text { CLASE } \\
\text { SOCIAL }\end{array}$ \\
\hline 20. Hombre & 24 & $\begin{array}{l}\text { Licenciado en ciencias de la información. Tra- } \\
\text { baja en un bar los fines de semana. Vive con } \\
\text { los padres y un hermano mayor. La madre tra- } \\
\text { baja a tiempo parcial y el padre es guardia de } \\
\text { seguridad. }\end{array}$ & MB \\
\hline \multicolumn{4}{|c|}{ CRISIS COMO OBSTÁCULO } \\
\hline 2. Mujer & 26 & $\begin{array}{l}\text { Graduada en psicología, desde unos meses } \\
\text { trabaja en prácticas en una consultoría, con- } \\
\text { fía tener pronto un contrato de colaboración. } \\
\text { Vive con los padres, ambos funcionarios, es } \\
\text { hija única. }\end{array}$ & MA \\
\hline 5. Hombre & 26 & $\begin{array}{l}\text { Licenciado en magisterio. Está cursando su } \\
\text { segunda licenciatura en Lengua Inglesa. Ha } \\
\text { trabajado en un centro comercial y en una } \\
\text { compañía de teatro. Quiere prepararse para } \\
\text { una oposición. Es hijo único, los padres es- } \\
\text { tán divorciados pero conviven en el mismo } \\
\text { hogar. }\end{array}$ & MA \\
\hline 6. Hombre & 26 & $\begin{array}{l}\text { Licenciado en derecho, está preparando una } \\
\text { oposición para ser funcionario. Trabaja en un } \\
\text { bar ocasionalmente. Vive con el padre, comer- } \\
\text { ciante, y con la madre, ama de casa. }\end{array}$ & MB \\
\hline 8. Hombre & 27 & $\begin{array}{l}\text { Licenciado en derecho, está preparando una } \\
\text { oposición para ser funcionario. Vive con su } \\
\text { familia en el centro de Madrid, los padres son } \\
\text { funcionarios, su hermana menor está estudian- } \\
\text { do y su hermana mayor vive con el novio. }\end{array}$ & MA \\
\hline 14. Mujer & 29 & $\begin{array}{l}\text { Licenciada en ingeniería química y en perio- } \\
\text { dismo. Es becaria en el Canal Isabel II y está } \\
\text { estudiando otra carrera, ingeniería industrial. } \\
\text { Ha vivido un año como Erasmus en Portugal } \\
\text { y, cuando regresó, decidió compartir piso en } \\
\text { alquiler con unas amigas. Después de unos } \\
\text { meses regresó a vivir con los padres. Cuando } \\
\text { se le acabe la beca quiere volver a vivir en el } \\
\text { extranjero. }\end{array}$ & MA \\
\hline
\end{tabular}




\begin{tabular}{|c|c|c|c|}
\hline ENTREVISTA & EDAD & SITUACIÓN ACTUAL & $\begin{array}{r}\text { CLASE } \\
\text { SOCIAL }\end{array}$ \\
\hline 16. Mujer & 27 & $\begin{array}{l}\text { Graduada en trabajo social. Está en paro, da } \\
\text { clases particulares de música y hace volunta- } \\
\text { riado en un centro social. Está haciendo un } \\
\text { curso de cooperación para el desarrollo. Em- } \\
\text { pezará a trabajar en una oNG dentro de dos } \\
\text { meses. Los padres están separados, ambos son } \\
\text { funcionarios. Vive con la madre y con dos her- } \\
\text { manos. }\end{array}$ & MA \\
\hline 17. Mujer & 25 & $\begin{array}{l}\text { Licenciada en empresariales, está a punto de } \\
\text { empezar un máster en administración y di- } \\
\text { rección de empresa. Ha sido becada en dos } \\
\text { empresas para hacer prácticas en los depar- } \\
\text { tamentos de selección de recursos humanos. } \\
\text { Trabaja en una agencia de catering y azafatas. } \\
\text { Vive con el padre policía, con la madre secre- } \\
\text { taria en una empresa y con una hermana. }\end{array}$ & MA \\
\hline 19. Hombre & 26 & $\begin{array}{l}\text { Licenciado en ciencias políticas. Becario en } \\
\text { un centro de investigación. Quiere viajar al } \\
\text { extranjero para hacer un máster y mejorar su } \\
\text { nivel de inglés. Quiere empezar un doctorado, } \\
\text { a condición de que esté becado. Es hijo único. } \\
\text { Vive con la madre, ama de casa, y con el padre, } \\
\text { comerciante. }\end{array}$ & MB \\
\hline \multicolumn{4}{|c|}{ CRISIS COMO OPORTUNIDAD } \\
\hline 3. Mujer & 30 & $\begin{array}{l}\text { Empezó a cursar la facultad de derecho, inte- } \\
\text { rrumpió la carrera para trabajar como auxiliar } \\
\text { administrativo en un estudio de abogados. En } \\
\text { esa temporada vivía en alquiler con su novio. } \\
\text { Después de dos años volvió a vivir con el pa- } \\
\text { dre, jubilado y ex jefe de ventas de una mul- } \\
\text { tinacional, y la madre, mientras que sus dos } \\
\text { hermanas mayores ya estaban fuera de casa. } \\
\text { Trabajó como tele-operadora, cuando se que- } \\
\text { dó en paro decidió volver a la universidad y } \\
\text { acabar los estudios en derecho. Ahora está } \\
\text { buscando trabajo como comercial en el mun- } \\
\text { do de la moda. }\end{array}$ & MA \\
\hline
\end{tabular}




\begin{tabular}{|c|c|c|c|}
\hline ENTREVISTA & EDAD & SITUACIÓN ACTUAL & $\begin{array}{l}\text { CLASE } \\
\text { SOCIAL }\end{array}$ \\
\hline 7. Mujer & 25 & $\begin{array}{l}\text { Licenciada en publicidad y relaciones públi- } \\
\text { cas. Después de un tiempo ha regresado al } \\
\text { hogar familiar por las dificultades para man- } \\
\text { tenerse económicamente. Es becaria en una } \\
\text { multinacional. Los padres son profesionales } \\
\text { autónomos y están divorciados. Es hija única y } \\
\text { vive con el padre. }\end{array}$ & MA \\
\hline 9. Hombre & 28 & $\begin{array}{l}\text { Licenciado en periodismo. Ha colaborado } \\
\text { con una organización para el desarrollo. Es } \\
\text { fotógrafo y bloguero. En breve se mudará a } \\
\text { Londres para una estancia de estudio. Vive en } \\
\text { casa de los padres, ambos son empleados: no } \\
\text { se especifica el sector de pertenencia pero el } \\
\text { mismo entrevistado afirma que su familia «no } \\
\text { tiene problemas económicos». }\end{array}$ & MA \\
\hline 10. Hombre & 26 & $\begin{array}{l}\text { Licenciado en ciencias económicas y empre- } \\
\text { sariales. Cobra el paro después de haber traba- } \\
\text { jado en una empresa de electrónica. Quiere vi- } \\
\text { vir en Alemania donde algunos amigos ya han } \\
\text { encontrado trabajo. El padre es un empresario } \\
\text { y la madre trabaja en un hospital. }\end{array}$ & MA \\
\hline 13. Hombre & 27 & $\begin{array}{l}\text { Licenciado en biología. Ha trabajado como } \\
\text { técnico en un laboratorio pero quiere dedi- } \\
\text { carse a otra profesión.Al momento está de alta } \\
\text { como trabajador autónomo. Ha vuelto a vivir } \\
\text { en casa con sus padres después haber termi- } \\
\text { nado la relación con una novia con la que al- } \\
\text { quilaba un piso. Después del verano volverá } \\
\text { a compartir piso con un amigo. Su padre ha } \\
\text { sido profesor universitario, ahora está jubila- } \\
\text { do. Tiene dos hermanos. }\end{array}$ & MA \\
\hline
\end{tabular}

